\title{
A POLÍTICA DE EDUCAÇÃO EM TEMPO INTEGRAL TRADUZIDA NOS \\ PME E PNME
}

\section{A qualidade do ensino em questão}

\author{
Eliene Brito Passos ${ }^{1}$ \\ Maria de Fátima Matos de Souza²
}

\begin{abstract}
RESUMO
Este trabalho tem por objetivo analisar os resultados obtidos na Prova Brasil realizada pela escola Amazônia, a partir da implantação dos Programas Mais Educação (PME) e Novo Mais Educação (PNME). Os dois programas foram implantados na escola em função dos baixos índices alcançados nos exames de larga escala nos anos em que participaram. A metodologia desenvolvida esteve pautada na abordagem qualitativa, tendo como técnica a pesquisa de campo. A coleta dos dados foi realizada por meio de entrevistas semiestruturadas com os participantes. Apesar do empenho da escola em preparar os alunos para a Prova Brasil, através das oficinas dos programas e de outras atividades implementadas, a meta projetada pelo MEC ainda não fora atingida. Portanto, a pesquisa permite apontar que, embora os resultados tenham tido um leve crescimento em 2019, ainda se está bem distante de atingir a meta proposta para 2021.
\end{abstract}

Palavras-chave: Políticas educacionais. Avaliação em larga escala. Programas educacionais.

\section{FULL-TIME EDUCATION POLICIES WITHIN THE PME AND PNME}

\section{Educational quality called into question}

\begin{abstract}
This work aims at analyzing results from the Prova Brasil standardized exam which took place in the Amazônia school, through the deployment of the dos Programas

\footnotetext{
1 Mestra em Currículo e Gestão da Escola Básica pela Universidade Federal do Pará (UFPA). Técnica em Educação-SEDUC/PA. Professora do Ensino Fundamental-SEMEC/Belém/PA Brasil. Pesquisadora do Grupo de Pesquisa em Política, Gestão e Avaliação da Educação (GPPGAE/UFPA). Orcid iD: https://orcid.org/0000-0001-5624-8935. E-mail: enapassos@yahoo.com.br

2 Pós-doutorado pela Universidade Católica de Brasília. Doutora em Educação Escolar pela Universidade Estadual Paulista Júlio de Mesquita Filho, Brasil (2007). Professora de carreira do magistério superior da Universidade Federal do Pará, Brasil. Professora do quadro permanente do Mestrado Acadêmico em Currículo e Gestão da Escola Básica - PPEB/ UFPA e do Doutorado em Educação, em Rede - Educanorte (UFOPA/UFPA). Universidade Federal do Pará (NEB/PPEB/ UFPA) - Brasil. Orcid iD: https://orcid.org/0000-0003-0214-8941. E-mail: fmatoz@gmail.com
} 
Mais Educação/ More Education Program (PME) e Novo Mais Educação / New More Education Program (PNME). Both programs had been implemented in that school due to low numbers reached in the large-scale exams joined by the school. The methodology applied consisted of a qualitative approach, with field research as its technique. Data collection was carried out through semi-structured interviews with program participants. Although the school efforts in preparing students to the Prova Brasil through workshops and other activities, the goal planned by the Ministry of Education has not been reached yet. Hence, the research allows us to point out how, despite a slight improvement in results in 2019, the school is far from reaching the proposed goal for 2021.

Keywords: Education policies. Large-scale exams. Educational programs.

\section{POLÍTICAS DE EDUCACIÓN A TIEMPO COMPLETO EN EL PME Y EL PNME La calidad educativa en cuestión}

\section{RESUMEN}

Este trabajo tiene como objetivo analizar los resultados del examen estandarizado Prova Brasil que se llevó a cabo en la escuela Amazônia, a través del despliegue de los dos Programas Mais Educação / Programa Más Educación (PME) e Novo Mais Educação / Programa Nuevo Más Educación (PNME). Ambos programas se habían implementado en esa escuela debido al bajo número alcanzado en los exámenes a gran escala a los que se sumó la escuela. La metodología aplicada consistió en un enfoque cualitativo, teniendo la investigación de campo como técnica. La recolección de datos se llevó a cabo a través de entrevistas semiestructuradas con los participantes del programa. A pesar de los esfuerzos de la escuela en preparar a los estudiantes para el Prova Brasil a través de talleres y otras actividades, la meta planificada por el Ministerio de Educación aún no se ha alcanzado. De ahí que la investigación nos permita señalar cómo, a pesar de una ligera mejora en los resultados en 2019, la escuela está lejos de alcanzar la meta propuesta para 2021.

Palabras clave: Políticas educativas. Exámenes a gran escala. Programas educativos.

\section{INTRODUÇÃO}

Este artigo é resultado de pesquisa de dissertação de mestrado, que teve como objeto de estudo o Programa Novo Mais Educação (PNME). Esse programa foi instituído pela Portaria Interministerial $n^{\circ} 1.144$ de 10 de outubro de 2016 (BRASIL, 2016a), para substituir o Programa Mais Educação (PME), que se encontrava em vigor desde 2007. As estratégias dos dois programas consistiam em desenvolver suas atividades no contraturno, uma vez que a extensão da jornada garantia aos alunos a permanência na escola por cerca de sete horas diárias. 
Embora a experiência de Educação Integral e Educação de Tempo Integral não seja nova no Brasil, iremos nos deter aqui nas experiências realizadas pelo PME a partir de 2007, as quais serviram de base para o PNME. De acordo com Arroyo (1988, p. 4), a primeira coisa sobre a qual refletir na educação seria "em quem se pensa quando se propõe uma escola de tempo integral". Isso, porque a escola pública que temos hoje certamente não recebe os filhos da elite brasileira. Portanto, ao pensar na ampliação de sua jornada, a escola precisa construir uma proposta pedagógica que vá ao encontro dos anseios e necessidades dos filhos dos trabalhadores. Esse deve ser o desafio de todo o poder público que pensa e propõe as políticas educacionais no Brasil.

Diante disso, este trabalho tem por objetivo analisar os resultados obtidos na Prova Brasil realizada pela escola Amazônia $^{3}$, a partir da implantação dos Programas Mais Educação (PME) e Novo Mais Educação (PNME). Os dados coletados para análise se referem ao período de 2007 a 2019, período de vigência dos dois programas na escola Amazônia.

Metodologicamente, este trabalho se pautou na abordagem qualitativa, uma vez que esta permitiu uma investigação mais detalhada do objeto de estudo. Assim, as técnicas de coleta de dados e levantamento de informações foram o levantamento bibliográfico e documental, além de entrevistas, as quais realizamos com a direção da escola e a articuladora do PNME. Fizemos também visitas exploratórias, que nos permitiram o acesso aos documentos arquivados do PME e do PNME. Este estudo pautou-se nas seguintes categorias: programas educacionais; avaliações externas; Educação Integral/ Educação de Tempo Integral.

Este artigo está estruturado em três partes, além desta introdução e das considerações finais. Na primeira, buscamos apresentar um pouco do percurso que a avaliação em larga escala tem feito no Brasil. Já na segunda, buscamos estabelecer um diálogo com os resultados dos exames

\footnotetext{
3 É uma escola da rede pública estadual de Belém/PA, que atende cerca de 1. 100 alunos em três turnos. Foi selecionada como lócus da pesquisa por ter sido contemplada com PME e PNME em função dos baixos índices alcançados na Prova Brasil, nos anos em que tem participado.
} 
em larga escala no Brasil. Na última parte, falamos dos desafios da escola Amazônia na busca pela elevação dos resultados nos exames nacionais de avaliação da aprendizagem, assim como buscamos fazer uma análise dos dados obtidos até o último exame realizado pela escola, em 2019.

\section{A INFLUÊNCIA DA AVALIAÇÃO EM LARGA ESCALA NA POLÍTICA DE TEMPO INTEGRAL NO BRASIL}

A temática da avaliação do sistema educacional surge nos anos 1980, a ponto de ganhar espaço na Constituição Federal de 1988 (BRASIL, 1988). Já na década de 90, esse tema ganha relevância ainda maior com a introdução de políticas educacionais, a exemplo da criação do Sistema de Avaliação da Educação Básica (Saeb), que, a partir de 1995, passa a realizar seu ciclo de avaliação a cada dois anos em todos os estados brasileiros.

Com a aprovação da nova Lei de Diretrizes e Bases da Educação 9.394/96 (BRASIL, 1996), questões que estavam em debate finalmente foram definidas, tais como o papel da União e das estruturas políticoadministrativas e normativas do Ministério da Educação (MEC) e do Conselho Nacional de Educação (CNE). A LDB introduziu dispositivos sobre avaliação, medida e controle na regulação da qualidade do ensino em escala nacional. De acordo com o Art. $9^{\circ}$, a União incumbir-se-á de:

\footnotetext{
$\checkmark$ - coletar, analisar e disseminar informações sobre a educação;

$\mathrm{VI}$ - assegurar processo nacional de avaliação do rendimento escolar no ensino fundamental, médio e superior, em colaboração com os sistemas de ensino, objetivando a definição de prioridades e a melhoria da qualidade do ensino;

$\S 2^{\circ}$ Para o cumprimento do disposto nos incisos $V$ a IX, a União terá acesso a todos os dados e informações necessários de todos os estabelecimentos e órgãos educacionais (BRASIL, 1996).
}

No excerto da legislação acima, fica explícito que é incumbência da União, em colaboração com os sistemas de ensino, o processo de avaliação educacional que vise à melhoria da qualidade da Educação Básica.

Em 2005, o Saeb foi reestruturado pela Portaria Ministerial n 931, de 21 de março de 2005 (BRASIL, 2005), passando a ser composto por duas 
avaliações: Avaliação Nacional da Educação Básica (Aneb) e Avaliação Nacional do Rendimento Escolar (Anresc); esta última é conhecida como Prova Brasil. Por sua vez, ambas se articulam, em 2007, com o Índice de Desenvolvimento da Educação Básica (Ideb). O resultado desse conjunto de avaliações tem influenciado diretamente as políticas públicas educacionais.

Em 2007, é também instituído pelo Decreto n 6.094, de 24 de abril de 2007 (BRASIL, 2007a), o Plano de Desenvolvimento da Educação (PDE) com várias estratégias, entre elas, o Plano de Metas Compromisso Todos pela Educação, cujo objetivo era a melhoria dos indicadores educacionais.

Em 2007, foi criado O PME 4, através da Portaria Normativa Interministerial $n^{\circ} 17 / 2007$ (BRASIL, 2007b), regulamentado pelo Decreto $n^{\circ}$ 7.083/2010, com o objetivo de contribuir para a melhoria da aprendizagem através da ampliação da jornada escolar, favorecendo então o alcance das metas pré-estabelecidas através do Ideb. O PME foi considerado pelo governo como programa indutor de políticas de Educação Integral no Brasil, de modo que fora ampliada a jornada escolar nas escolas públicas das redes estaduais e municipais de ensino para no mínimo sete horas diárias.

A Educação Integral proposta no PME amplia tempos, espaços e conteúdo, buscando constituir uma educação cidadã, com contribuições de outras áreas sociais e organizações da sociedade civil. A Educação Integral busca garantir o pleno desenvolvimento de crianças, adolescentes e jovens, propiciando múltiplas oportunidades de aprendizagem por meio da ampliação do tempo e do acesso à cultura, à arte, ao esporte, à ciência e às tecnologias, entre outros. Moll (2012) tinha preocupação com a ampliação da jornada escolar, esclarecendo que esta objetivava a modificação da rotina da escola para que não incorresse no "mais do mesmo", ou seja, os alunos no contraturno deveriam ser inseridos em experiências novas e desafiadoras, e as experiências do programa deveriam dialogar com as atividades contidas na proposta pedagógica da escola.

\footnotetext{
4 As atividades tiveram início em 2008, com a participação de 1.380 escolas, em 55 municípios, nos 26 estados e no Distrito Federal, atendendo 386 mil estudantes (BRASIL, 2020).
} 
Mesmo com todas essas mudanças na rotina de muitas escolas públicas, o que tínhamos no Brasil era um cenário político marcado pela avaliação em larga escala em todos os níveis e modalidades de ensino. Isso se dava porque esse tipo de avaliação tem como meta medir a eficácia do sistema escolar, a fim de avaliar a qualidade do ensino e subsidiar as políticas educacionais.

Já a avaliação dentro de um contexto de Educação de Tempo Integral busca incluir, ainda que de forma distinta, os sujeitos envolvidos no processo educativo, considerando as particularidades e variações às quais as redes educacionais brasileiras estão submetidas.

Ao assumir a Presidência da República em 2016, o presidente Michel Temer encerra o PME e institui o Programa Novo Mais Educação (PNME), através da Portaria Interministerial n 1.144/2016 (BRASIL, 2016a), como uma política do governo federal que tem o objetivo de melhorar a aprendizagem dos alunos em língua portuguesa e matemática no ensino fundamental; o programa traz consigo uma concepção de educação centrada em alcance de resultado, quando visa sobretudo à melhoria do aprendizado a partir dos indicadores traçados, conforme retrata o Caderno de Orientações Pedagógicas - Versão l:

Desta forma o Novo Mais Educação é uma estratégia que necessariamente conduz a escola a se autoavaliar. Representa uma oportunidade de pensar no processo de alfabetização e letramento de crianças e adolescentes, nos processos avaliativos, nas taxas de evasão e reprovação, enfim, de pensar nos seus resultados a partir de indicadores educacionais (BRASIL, 2017, p. 4).

A esse respeito, Lima (2012) nos chama atenção para a crescente centralidade das políticas baseadas na evidência, isto é, uma espécie de "governo pela avaliação dos resultados", em que o governo se utiliza dos resultados mensurados em exames de larga escala para planejar, implantar e/ou implementar os programas educacionais no país.

A política de avaliação baseada em resultados vem sendo cada vez mais comum na educação brasileira, disseminando a lógica de mercado para o sistema público, por meio da gestão gerencial, que resulte em 
eficiência, produtividade, responsabilização e controle dos resultados, contradizendo os princípios da gestão democrática na educação, uma vez que "os princípios que são eficientes para atingir os fins da empresa capitalista não podem ser igualmente eficientes para atingir os fins da escola" (PARO, 2011, p. 37).

A busca por melhores "resultados" merece estudos mais aprofundados, a fim de se compreender até que ponto a formação humana vem sendo priorizada. Diante desse novo cenário, pesquisadores brasileiros, como Paro $(2011$, 2015, 2016), Satyro e Soares (2007), Paz (2013) e Oliveira e Souza (2015), entre outros, vêm intensificando estudos que permitem compreender fatores que tanto determinam a educação de qualidade 5 quanto influenciam positivamente o ensino e o desempenho dos discentes. Libâneo, Oliveira e Toschi (2007, p. 117) nos dizem que a:

\begin{abstract}
Educação de qualidade é aquela mediante a qual a escola promove para todos, o domínio dos conhecimentos e desenvolvimento de capacidades cognitivas e afetivas indispensáveis ao atendimento de necessidades individuais e sociais dos alunos, bem como a inserção no mundo e a constituição da cidadania também como poder de participação, tendo em vista a construção de uma sociedade mais justa e igualitária. Qualidade é, pois, conceito implícito à educação e ao ensino.
\end{abstract}

Partindo desse princípio em que a qualidade é um conceito implícito à educação e ao ensino, não podemos aceitar como natural que a escola pública não oferte um ensino de qualidade. Preferimos entender que esse é um grande desafio que se coloca a todos os brasileiros, uma vez que há uma grande quantidade de indivíduos excluídos e sem condições básicas para se constituírem enquanto cidadãos partícipes de uma sociedade em permanente mutação. Portanto, a qualidade da educação não deveria ser ofertada apenas para alguns, mas para todos. Esse é o desafio de uma sociedade de classes.

5 O artigo 206, inciso VII, da Constituição Federal faz menção explícita à importância da qualidade da educação, tratando-a como um princípio basilar do ensino a ser ministrado, ou seja, garante o direito à educação com "padrão de qualidade" para todos (BRASIL, 1988). 
É pertinente aqui mencionar que tanto o PME como o PNME foram instituídos para atender aos alunos com mais dificuldade na aprendizagem; desse modo, suas atividades não estavam voltadas para o atendimento de todos os educandos da rede pública de ensino. Isso contradiz o termo "ensino de qualidade", conforme refletem Libâneo, Oliveira e Toschi (2007). Não devemos esquecer como, em uma escola que se pretenda democrática, inclusiva e integral, as práticas avaliativas deveriam se pautar em garantir que, no limite, todos aprendam tudo e tenham acesso a todas as atividades ofertadas pela instituição.

Já quando o propósito é a melhoria da qualidade do ensino, não podemos deixar de mencionar que há vários fatores envolvidos. De acordo com Satyro e Soares, não podemos esquecer que a infraestrutura afeta diretamente a qualidade da educação, pois:

Prédios e instalações inadequadas, a inexistência de bibliotecas, espaços esportivos e laboratórios, a falta de acesso a livros didáticos, materiais de leitura, a relação inadequada ao tamanho da sala de aula e o número de alunos são problemas que influenciam diretamente no desempenho dos alunos (SATYRO; SOARES, 2007, p. 7).

Essa fala dos autores é significativa, porque, quando o PME e o PNME foram implantados, eles demandaram, sobretudo, infraestrutura para que as atividades dos programas acontecessem no contraturno. Todavia, a precariedade das escolas públicas é um ponto frágil da educação brasileira, podendo influenciar diretamente na aprendizagem. Portanto, é relevante compreender que a falta de uma boa infraestrutura gera entraves no aprendizado, principalmente para as crianças que mais carecem dos recursos os quais apenas as escolas poderiam oferecer; a exemplo de uso de tecnologia, laboratórios e biblioteca, aos quais estes alunos não possuem acesso.

A escola pública vem padecendo há muito tempo por falta de investimentos em todos os campos, quer estrutural, quer pedagógico. No entanto, por ser espaço privilegiado de construção do conhecimento, deveria receber todo o empenho necessário para que os alunos 
alcançassem o máximo de seu desempenho. Sobre esse debate, Paro (2016, p. 132) também contribui quando diz que "não há dúvida de que é preciso mudar quase tudo na forma de operar das escolas, mas a condição primeira é provê-las dos recursos materiais e financeiros necessários para isso".

No entanto, ainda é necessário muito mais engajamento por parte do poder público, para que condições dignas de ensino e de aprendizagem nos espaços educativos sejam garantidas aos trabalhadores da educação e aos alunos. A esse respeito, Vieira (2007) afirma que a finalidade da educação é promover o ensino e a aprendizagem, viabilizando a educação como um direito de todos, conforme determinam a Constituição Federal (BRASIL, 1988) e a Lei de Diretrizes e Bases n 9.394/96 (BRASIL, 1996).

Quando falamos de educação enquanto um direito de todos, não podemos pensar só no direito à matrícula; precisamos pensar no direito à aprendizagem, pois isso é direito à educação, sobretudo de qualidade. Paro (2011, p. 137-138) corrobora a ideia da seguinte forma:

Quando falamos de direito à educação, portanto, isso não pode significar o direito apenas a pequenos "pedaços" da cultura, na forma das chamadas disciplinas escolares (Matemática, Geografia, Língua Portuguesa, etc.). Estas são, sem dúvida, partes importantíssimas da herança cultural, mas não são tudo.

Infelizmente, esse foco nas disciplinas ainda é realidade nas escolas brasileiras, especialmente se considerarmos que o PNME se apresentou nas escolas como um "reforço" no contraturno com o objetivo de melhorar a aprendizagem das crianças e adolescentes com dificuldades de aprendizagem, justamente para que os resultados se elevassem nos exames realizados a cada dois anos pelo MEC.

De acordo com o Instituto Nacional de Ensino e Pesquisa (Inep), o Brasil precisa atingir a média 6,0 no Índice de Desenvolvimento da Educação Básica (Ideb) 6 até 0 ano de 2021; isso, em razão de ser este o ano que antecede a comemoração do bicentenário da independência do Brasil.

\footnotetext{
6 Ideb é o Índice de Desenvolvimento da Educação Básica, criado em 2007, pelo Instituto Nacional de Estudos e Pesquisas Educacionais Anísio Teixeira (Inep), formulado para medir a qualidade do aprendizado nacional e estabelecer metas para a melhoria do ensino.
}

Revista Exitus, Santarém/PA, Vol. 11, p. 01 - 24, e020199, 2021. 
Essa média é para os anos finais do ensino fundamental, o que equivale ao nível dos países desenvolvidos7. Decorre daí então a importância de estudos e pesquisas empíricas capazes de revelar a verdadeira face da escola, que nem sempre está expressa nos exames em larga escala, mas a qual é importante apresentar, uma vez que seus achados respaldam as políticas educacionais direcionadas à melhoria da qualidade da educação.

\section{OS RESULTADOS DOS EXAMES EM LARGA ESCALA NO BRASIL: A CORRIDA PELAS MELHORES POSIÇÕES NOS RANKINGS EDUCACIONAIS}

Para compreender melhor a relação dos exames em larga escala e a qualidade da educação, é pertinente citarmos a meta 7 do PNE (2014-2024), que estabelece o IDEB como parâmetro oficial de qualidade da Educação Básica nacional.

A Meta 7 consiste em fomentar a qualidade da Educação Básica em todas as etapas e modalidades, com melhoria do fluxo escolar e da aprendizagem, de modo a atingir progressivamente, até 2021, as seguintes médias nacionais para o Ideb: a) 6,0 para os anos iniciais do ensino fundamental; b) 5,5 nos anos finais do ensino fundamental; e c) 5,2, no ensino médio. Essa média de qualidade é obtida em 2003 pelos países desenvolvidos que participam do Programme for International Student Assessment (PISA), no caso dos anos finais (6a a $9^{a}$ séries) (SCHNEIDER; NARDI, 2014).

Esse é um desafio posto ao Brasil desde 2007, e cujo resultado final será divulgado em 2022, ano do bicentenário da Independência do Brasil. Só então os resultados obtidos serão oficialmente comparados com os países desenvolvidos que fazem parte da Organização para a Cooperação e Desenvolvimento Econômico (OCDE) (PAZ, 2013).

É importante ressaltar que, no campo educacional, vem sendo cada vez mais frequente a utilização desses indicadores estatísticos para a

\footnotetext{
7 As metas são diferenciadas para todos, cada unidade, rede e escola, e são apresentadas bienalmente de 2007 a 2021, de modo que os estados, municípios e escolas deverão melhorar seus índices e contribuir, em conjunto, para que o Brasil chegue à meta 6,0 em 2022, ano do bicentenário da Independência <http://portal.mec.gov.br/conheca-o-ideb>.
} 
definição de políticas públicas educacionais. O argumento está na elevação da qualidade da educação, o que vem resultando na implantação de programas e projetos nas escolas. No entanto, medir a qualidade do ensino através dos exames em larga escala não é um consenso entre os brasileiros e muito menos entre os pesquisadores. Sobre isso, Oliveira (2018, p. 56) acredita que: "Entre outros problemas e equívocos, a meta 7 do PNE reduz a compreensão da melhoria do ensino à melhoria do IDEB das escolas, quantificando resultados a partir de graus em provas e índices de permanência e aprovação escolar".

Essa questão assume relevância quando consideramos que os indicadores de qualidade não são apenas o movimento e rendimento que o IDEB toma como base ao aferir a avaliação realizada pela escola. Antes, é preciso que o sistema avaliador considere fatores econômicos, políticos e sociais, uma vez que vivemos em um país intercontinental, e que tem uma história marcada por lutas e diferenças de classes.

Os exames em larga escala, também chamadas de avaliações externas, são assim denominados porque são definidos, organizados e conduzidos por quem não se encontra no interior das escolas. Com isso, as avaliações padronizadas são aplicadas a cada dois anos aos estudantes do $5^{\circ}$ e do $9^{\circ}$ ano do ensino fundamental e da $3^{a}$ série do ensino médio.

As informações são coletadas a partir da realização de um exame de proficiência em Língua Portuguesa (leitura) e Matemática (resolução de problemas) e pelos dados de um questionário destinado a diretores e professores de todas as escolas, a cada edição do exame. Por sua vez, a Prova Brasil compreende uma avaliação também externa, realizada nas mesmas disciplinas do Saeb e com a mesma frequência (bianualmente). Porém, ao contrário do Saeb, ela tem abrangência censitária, ou seja, avalia o desempenho dos estudantes de $5^{a}$ e $9^{a}$ séries do ensino fundamental de todas as escolas públicas com pelo menos 20 alunos, situadas nas áreas rural e urbana do país (SCHNEIDER; NARDI, 2014).

As avaliações em larga escala têm permitido monitorar o funcionamento de redes de ensino e fornecer subsídios para seus gestores na 
formulação de políticas educacionais com dados mais bem definidos em termos dos resultados, que, por sua vez, decorreriam das aprendizagens dos alunos.

O grande motivador das avaliações em larga escala está vinculado à necessidade de dados concretos para a elaboração e execução de políticas educacionais. No entanto, esses exames em larga escala têm levantado também o debate sobre accountability na educação, por ser também considerado uma espécie de prestação de contas ou responsabilização, ainda que sua concepção atual não se esgote nesses dois vocábulos (SCHNEIDER; NARDI, 2014).

Esse é um debate que tem ganhado força ao considerar que tais exames estão associados a um discurso político-ideológico e são orientados por reformas na administração pública do país, as quais vêm ocorrendo mais intensamente a partir dos anos de 1990. "Não obstante, o índice constitui-se a partir de indicadores que visam, predominantemente, o exercício de prestação de contas e de controle por parte do Estado" (SCHNEIDER; NARDI, 2014, p. 23).

Sobre esse debate, Chirinéa e Brandão (2015, p. 463) também acrescentam que "[...] a reforma do Estado, proposta na década de 1990, vai delinear as políticas educacionais no Brasil, na medida em que propõe a avaliação externa como mecanismo de controle e regulação do Estado". Portanto, a relação existente entre os exames em larga escala e a qualidade da educação possui uma linha bastante tênue, o que exige de todos os legisladores, quer em esfera municipal, estadual ou federal, um olhar para além dos resultados. Somente assim as políticas de enfrentamento dos baixos índices que a educação brasileira tem apresentado serão, de fato, exequíveis do ponto de vista da melhoria da aprendizagem, e não apenas de índices.

Vale ressaltar a existência de vários fatores que influenciam na qualidade do ensino, tais como: nível socioeconômico e cultural dos alunos; formação docente; valorização do magistério; condições materiais e imateriais de trabalho; gestão escolar; infraestrutura da escola, e outros. 
Portanto, os exames em larga escala, com foco em Língua Portuguesa e Matemática, não contemplam todos esses aspectos que englobam a educação.

Ao comparamos as versões do PME com o PNME no que se refere aos aspectos das atividades de acompanhamento pedagógico, na versão de 2007, a escola deveria contemplar obrigatoriamente pelo menos uma atividade de acompanhamento pedagógico; as outras três atividades deveriam ser escolhidas dentre os demais macrocampos. Já no PNME, a escola só poderá oferecer atividades de arte, cultura, esporte e lazer, se fizer opção por 15 horas semanais; caso a opção seja por 5 horas semanais, só poderá realizar as atividades de acompanhamento pedagógico de língua portuguesa e de matemática, o que demonstra a lógica da ênfase nos resultados, no reforço de aprendizagem e não na formação integral do ser humano.

Essa ênfase nos resultados é inclusive destacada por Rinaldi e Rinaldi (2020) quando reportam sobre a finalidade do PNME, que tem foco nos resultados das avaliações externas.

De acordo com Artigo $2^{\circ}$ da Portaria $n^{\circ} 1.144 / 2016$, o PNME tem por finalidade contribuir para a:

I - alfabetização, ampliação do letramento e melhoria do desempenho em língua portuguesa e matemática das crianças e dos adolescentes, por meio de acompanhamento pedagógico específico;

II - redução do abandono, da reprovação, da distorção idade/ano, mediante a implementação de ações pedagógicas para melhoria do rendimento e desempenho escolar;

III - melhoria dos resultados de aprendizagem do ensino fundamental, nos anos iniciais e finais.

IV - ampliação do período de permanência dos alunos na escola (BRASIL, 2016a).

A Portaria $n^{\circ} 1.144 / 2016$ do PNME não explicita no corpo do documento uma concepção de educação centrada no desenvolvimento integral do ser humano; menciona apenas no inciso IV, como uma de suas finalidades, a ampliação do período de permanência dos alunos na escola. Portanto, é possível perceber que o PNME não possui uma perspectiva de 
desenvolvimento humano centrado na integralidade autônoma, crítica e reflexiva, capaz de formar sujeitos autores de sua própria aprendizagem, transformadores de sua realidade, e por fim cidadãos emancipados democraticamente para agir e viver em sociedade. Fica então muito clara uma política educacional pautada no alcance de resultados do índice de Desenvolvimento da Educação Básica (IDEB), especialmente quando se fala na melhoria do desempenho apenas de Língua Portuguesa e Matemática.

\section{OS DESAFIOS dA ESCOLA "AMAZÔNIA" eM BuSCA dA ELEVAÇÃo de SEUS RESULTADOS NA AVALIAÇÃO EM LARGA ESCALA}

A escola Amazônia possui 24 salas de aula, laboratório de informática, sala multifuncional, biblioteca, sala de multimídia e quadra de esporte. Está situada dentro de um bairro com moradores de classe média e de baixa renda; e seu alunado é basicamente composto por crianças, jovens e adultos, com nível socioeconômico diversificado (trabalhador doméstico, mercado informal etc.), com renda de até dois salários-mínimos.

Cabe destacar que a educação brasileira sofreu várias reformas e transformações nas últimas décadas, e o que temos visto são políticas públicas que foram estabelecidas pelo governo federal na tentativa de colocar o Brasil em condições parecidas com as dos países desenvolvidos.

Dessa forma, têm chegado às escolas públicas brasileiras programas e projetos cujo objetivo é elevar os índices de aprendizagem que os exames em larga escala apresentam a cada dois anos. Por apresentar baixos índices de aprendizagem, a escola "Amazônia" foi inserida na relação de escolas beneficiadas pelas políticas educacionais que visam à melhoria dos índices de desempenho, portanto, foi contemplada tanto com o PME quanto com o seu substituto, o PNME.

A escola "Amazônia" tem participado desse processo desde 2005, exceto nos anos de 2011 e 2017, quando não atingiu o número mínimo de frequência obrigatória no dia da aplicação dos testes. Sua adesão ao PME ocorreu em 2010, e as oficinas do programa foram desenvolvidas junto aos alunos até 2015, quando o programa teve suas atividades encerradas, sendo 
substituído no ano seguinte por outro programa. Assim sendo, é possível olhar e analisar os dados que a escola vem alcançando quando os dois programas estavam em plena execução.

A escola pesquisada chegou a executar o PME por cerca de cinco anos; já o PNME durou apenas oito meses (março a novembro de 2018), quando os recursos financeiros acabaram, ficando no aguardo de que as atividades tivessem prosseguimento, o que não aconteceu até o término da pesquisa, em novembro de 2019.

Levamos em consideração aqui o estabelecido na estratégia 7.2 da Meta 7 , segundo a qual pelo menos $70 \%$ dos alunos devem estar no nível suficiente de aprendizado no quinto ano de vigência do PNE, e todos os estudantes devem alcançar esse nível no último ano de sua vigência. Em razão disso, julgamos pertinente analisar os dados que a escola Amazônia vem apresentando ao longo dos anos em que tem participado dos exames em larga escala realizados pelo MEC.

$\mathrm{Na}$ Tabela 1, apresentamos os dados observados e as metas projetadas, tanto para a escola pesquisada quanto para o estado do Pará e - Brasil, o que nos permite fazer uma análise comparativa dos índices alcançados nessas esferas participantes do processo avaliativo em larga escala.

Tabela 1 - Resultados do Ideb de 2019 da EEEFM "Amazônia" - 4ª série /5ª ano

\begin{tabular}{|c|c|c|c|c|c|c|c|c|c|c|c|c|c|c|c|c|}
\hline & \multicolumn{6}{|c|}{ Ideb Observado } & \multicolumn{8}{|c|}{ Metas Projetadas } & \multirow[b]{2}{*}{2019} & \multirow[b]{2}{*}{2021} \\
\hline & 2005 & 2007 & 2009 & 2011 & 2013 & 2015 & 2017 & 2019 & 2007 & 2009 & 2011 & 2013 & 2015 & 2017 & & \\
\hline $\begin{array}{l}\text { EEFM } \\
\text { Amazônia }\end{array}$ & 3.3 & 2.2 & 3.0 & - & 3.3 & 3.6 & - & 4.5 & 3.4 & 3.7 & 4.1 & 4.4 & 4.7 & 5.0 & 5.3 & 5.6 \\
\hline $\begin{array}{l}\text { Estado do } \\
\text { Pará }\end{array}$ & 2,8 & 2,8 & 3,7 & 4,0 & 3,6 & 4,2 & 4,5 & 5,0 & 2,8 & 3,2 & 3,6 & 3,8 & 4,1 & 4,4 & 4,7 & 5,1 \\
\hline Brasil & 3,8 & 4,2 & 4,6 & 5,0 & 5,2 & 5,5 & 5,8 & 5,9 & 3,9 & 4,2 & 4,6 & 4,9 & 5,2 & 5,5 & 5,7 & 6,0 \\
\hline
\end{tabular}

Fonte: MEC - INEP - Instituto Nacional de Estudos e Pesquisas Educacionais Anísio Teixeira

Como mostra a Tabela 1, em nenhum momento a escola Amazônia atingiu ou superou a meta projetada para a escola pelo INEP, ficando sempre abaixo de tal projeção. Em 2005, obteve 3,3, mas caiv em 2007 para 2,2; a partir daí, embora viesse crescendo nos resultados, não superava sua 
meta nem conseguia em nenhum momento superar a nota estadual ou nacional, como demonstram os dados.

Vale aqui acrescentar que foram justamente esses baixos índices que credenciaram a escola Amazônia a receber os PME e PNME, que visam à melhoria dos resultados, uma vez que foram criados pelo Governo Federal para o enfrentamento dos baixos resultados apresentados pela maioria das escolas públicas brasileiras.

Os dados da Tabela 1 são bastante inquietantes, e aqui vamos olhar mais diretamente para 2011, 2013 e 2015, pois, nesses anos de avaliação da Prova Brasil, os discentes com dificuldades de aprendizagem já estavam participando das atividades do PME que aconteciam no contraturno; isso se dava por meio de atividades optativas em macrocampos, assim denominados: acompanhamento pedagógico; meio ambiente, esporte e lazer; direitos humanos em educação, cultura e artes, cultura digital, promoção da saúde; educomunicação, investigação no campo das ciências e natureza e educação econômica. No entanto, não há uma elevação expressiva dos resultados; inclusive em 2011, a escola nem chegou a atingir o mínimo de frequência dos alunos para que sua pontuação fosse divulgada. Embora nos anos subsequentes de avaliação nacional (2013 e 2015), a escola tenha apresentado um leve crescimento, ainda assim continuou sem atingir sua meta e ficou abaixo da nota alcançada pelo estado do Pará e pelo Brasil.

A escola Amazônia teve também os anos finais do ensino fundamental avaliados pela Prova Brasil, conforme mostra resultado da tabela a seguir.

Tabela 2 - Resultados do Ideb de 2019 da EEEFM “Amazônia" - 8ª série/9ª ano

\begin{tabular}{|c|c|c|c|c|c|c|c|c|c|c|c|c|c|c|c|c|}
\hline & \multicolumn{8}{|c|}{ Ideb Observado } & \multicolumn{8}{|c|}{ Metas Projetadas } \\
\hline & 2005 & 2007 & 2009 & 2011 & 2013 & 2015 & 2017 & 2019 & 2007 & 2009 & 2011 & 2013 & 2015 & 2017 & 2019 & 2021 \\
\hline $\begin{array}{l}\text { EEFM } \\
\text { Amazônia }\end{array}$ & 2.9 & 2.2 & 3.1 & - & 2.2 & 3.3 & - & 3.8 & 3.0 & 3.1 & 3.4 & 3.8 & 4.2 & 4.4 & 4.7 & 5.0 \\
\hline $\begin{array}{l}\text { Estado do } \\
\text { Pará }\end{array}$ & 3,1 & 2,9 & 3,1 & 3,1 & 3,0 & 3,2 & 3,3 & 3,8 & 3,2 & 3,3 & 3,6 & 4,0 & 4,4 & 4,6 & 4,9 & 5,2 \\
\hline Brasil & 3,5 & 3,8 & 4,0 & 4,1 & 4,2 & 4,5 & 4,7 & 4,9 & 3,5 & 3,7 & 3,9 & 4,4 & 4,7 & 5,0 & 5,2 & 5,5 \\
\hline
\end{tabular}

Fonte: MEC - Inep - Instituto Nacional de Estudos e Pesquisas Educacionais Anísio Teixeira 
A Tabela 2, com os dados dos anos finais do ensino fundamental, mostra que resultados também foram baixos, embora tenham atingido a meta projetada para 2009. No entanto, nos anos subsequentes, a escola não conseguiu melhorar seu quadro no Ideb. Todavia, em 2015, ela supera a nota estadual por um ponto e, em 2019, ela tira a mesma nota da rede estadual, ainda assim ficando bem abaixo da média nacional. Com isso, ainda precisaria avançar bastante para atingir ou superar a meta projetada para o ano de 2021, que é de 5,0.

Apesar do empenho da escola em preparar os alunos para participarem da Prova Brasil, através das oficinas dos programas e de outras atividades implementadas pela gestão escolar, a meta projetada para escola ainda não foi atingida nos anos em que participou, apesar de se reconhecer que a escola vem apresentando um leve crescimento em seus resultados.

Muito embora o IDEB correspondente ao ano de 2019, tanto dos anos iniciais quanto dos anos finais, tenha apresentado crescimento, o fato é que ainda está distante da média que os países desenvolvidos da Organização para a Cooperação e Desenvolvimento Econômico (OCDE) têm nessa escala, qual seja, 7.

Contudo, resultados iguais a esses da escola Amazônia também são identificados em outros estudos, a exemplo do estudo de Bernardo e Christovão (2016), realizado nas escolas do Rio de Janeiro, o qual identifica a mesma situação:

[...] com a implantação do programa, a partir de 2007, poderíamos esperar um aumento deste índice para as escolas selecionadas, tendo em vista o investimento realizado. Ainda que a diferença entre as médias para os dois grupos de escolas apresente uma leve tendência de diminuição entre 2005 e 2011, em 2013 ela volta a crescer, mesmo diante da queda apresentada pelo conjunto total de escolas para os valores médios do IDEB 2013. Ou seja, mesmo sem que pudéssemos tirar conclusões do tipo causal sobre os dados apresentados, não foi possível verificar indícios positivos satisfatórios no tocante à relação entre a implantação do Programa Mais Educação e alguma melhoria nos indicadores de desempenho das escolas de anos iniciais do ensino fundamental da rede municipal do Rio de Janeiro ao longo dos últimos anos [...] (BERNADO; CHRISTOVÃO, 2016, p. 1128). 
Assim como na escola pesquisada pelas autoras acima, a escola Amazônia também não apresentou índices positivos satisfatórios, mesmo com os programas Mais Educação e Novo Mais Educação, utilizados como alternativa para elevar o ldeb.

Hojas (2013) discute também o conceito de qualidade de ensino utilizado nas políticas de larga escala adotadas no Brasil e diz que a referência são as experiências internacionais, o que acaba sendo contraditório, pois como apresentar resultados compatíveis com a qualidade dos países desenvolvidos, se temos realidades distintas que merecem atenção e melhores investimentos? É importante acrescentar que o PME tinha recursos financeiros para material pedagógico, custeio de oficinas etc.

Já o PNME foi implantado com recursos destinados basicamente para a cobertura de despesas com transporte e alimentação dos mediadores e facilitadores responsáveis pelo desenvolvimento das atividades do programa, ou seja, um novo programa com cortes nos recursos financeiros, redução das oficinas oferecidas aos alunos e da implementação do reforço escolar no contraturno. De fato, é preciso rever o conceito de "qualidade de ensino", pois a retirada de investimentos dificilmente resultará em mais qualidade, mesmo que a escola pesquisada tenha melhorado o seu último índice quando comparado aos anos anteriores. Sobre isso, Paz $(2013$, p. 109) diz que:

\footnotetext{
Duras críticas têm sido tecidas contra esse tipo de avaliação, visto que desconsideram que parte dos problemas educacionais que advém do próprio formato do projeto ideológico neoliberal, no qual se reduz a qualidade da igualdade de acesso às escolas, mas em contrapartida, se estimula a competição e o ranqueamento entre elas, gerando espaço para ricos e espaços para pobres, segregando ainda mais as camadas populares no interior dos sistemas de ensino.
}

A fala da autora é condizente com os programas implantados na escola pesquisada, pois, dos quase 1.100 alunos, apenas 200 foram selecionados para participar das atividades do programa no contraturno, tanto no PME quanto no PNME. Ainda de acordo com Paz (2013), esse tipo de avaliação é, na verdade, um instrumento limitado para avaliar a 
Educação Básica por não considerar outros indicadores importantes no processo de avaliação. Dessa forma, as críticas de Paz (2013) são pertinentes, pois há a necessidade do protagonismo dos sujeitos envolvidos no processo de planejamento das políticas públicas educacionais, a fim de que não sejam tão somente metas pensadas e projetadas a partir de dados estatísticos sem nexo com a realidade na qual a escola está inserida. De acordo com Paro (2015, p. 64):

\begin{abstract}
Infelizmente, é a visão do senso comum que orienta de modo geral as políticas públicas em educação, entre nós, com o agravante de que as próprias metas do ensino têm se reduzido a rudimentos de Matemática e Língua Portuguesa que são pretensamente aferidos por meios dos duvidosos sistemas de "avaliação" em ampla escala como Saeb, a Prova Brasil, etc., cuja principal função tem sido escamotear ainda mais os reais problemas de nosso ensino.
\end{abstract}

Essa fala de Paro se comprova na realidade pesquisada, uma vez que, como demonstrado nas Tabelas 1 e 2, a escola "Amazônia" apresenta baixos resultados nos exames da Prova Brasil desde 2007. Entretanto, mais do que atingir a meta ou mesmo prestar contas (accountability) para os sistemas de ensino, o compromisso não somente da escola "Amazônia", como das demais escolas, deveria ser o de elevar a qualidade de todos os seus processos pedagógicos. Portanto, o PME e PNME são parte de uma política de governo que muitas vezes aparenta mais preocupação com resultados do que com a formação integral do aluno.

A equipe que dirigia a escola na ocasião da realização da pesquisa tinha assumido a gestão no final de 2016. Quando questionados sobre a contribuição do PNME para a melhoria da aprendizagem dos alunos, as respostas foram:

Quando eu cheguei, nós tínhamos um aluno que tinha um comportamento diferenciado. Ele era de pouca concentração, de pouca valorização do espaço escolar. Eu, enquanto diretora, gosto muito de falar [...]. Aí eu digo, eu acho que nós alcançamos nosso objetivo né? Que, por meio do diálogo, fazer o aluno se tornar sujeito da aprendizagem naquela comunidade escolar (Diretora).

Contribuiu sim! Porque, se a gente for comparar os dados de 2017 com 2018, diminuiu muito a questão da retenção e o número de alunos com dependência também, entendeu? Por exemplo, no ano

Revista Exitus, Santarém/PA, Vol. 11, p. 01 - 24, e020199, 2021. 
de 2017 para 2018, quando a gente formou as turmas, dava pra fazer uma turma só de dependência, nossa! (Articuladora).

Contribuiu sim. Você pode ver também a questão das notas e você vê um crescimento considerável em relação às crianças que não fizeram atividades. A gente vê, assim, que foi um divisor de águas, crianças que não participaram do programa e crianças que participaram das atividades do PNME (Vice-diretora).

As falas acima nos permitem dizer que já havia, por parte da equipe gestora da escola, uma expectativa de que o resultado de 2019 seria melhor por conta do que a equipe já visualizava cotidianamente na aprendizagem dos alunos.

Contudo, faz-se necessária uma intervenção efetiva na implantação de políticas públicas educacionais que visem à superação da deficiência estrutural do sistema, pois as mesmas vêm sendo pensadas e implantadas pelo Governo Federal sem um debate amplo e consistente acerca do que realmente atenderia às necessidades de cada região, estado, comunidade, escola etc.

De acordo com Moraes (2014, p. 97), "é no espaço escolar que a maioria dos alunos tem a oportunidade de apropriar-se dos instrumentos que Ihe permitem a participação crítica e ativa na sociedade e isso é fundamental para o exercício pleno da cidadania". Portanto, quando são inseridos na dinâmica escolar, pressupomos que terão suas ações executadas com empenho e responsabilidade, a fim de garantir resultados positivos não somente em exames cujos objetivos sejam mensurar desempenho, mas, sobretudo, garantir a aprendizagem dos alunos e que esses resultados possam se refletir em todos os processos e etapas de suas vidas de forma positiva.

Os dados apresentados nas Tabelas 1 e 2 revelam que há muito a ser feito pelos governantes e servidores educacionais, até que a nota 6,0 seja atingida por grande maioria das escolas públicas, principalmente no ensino fundamental maior, em que se encontram os resultados mais baixos. Talvez seja relevante pensar em políticas de Estado em vez de políticas de governo 
para o enfrentamento dos baixos índices de aprendizagem que os dados revelam.

\section{CONSIDERAÇÕES FINAIS}

A discussão proposta neste artigo, sobre os resultados da Prova Brasil, busca sobretudo entender se a aprendizagem dos alunos tem melhorado com a implantação/implementação dos PME e PNME na escola Amazônia. O estudo foi realizado a partir do percurso que as avaliações em larga escala têm feito no Brasil, assim como da implantação dos PME e PNME na escola Amazônia. Assim, essa incursão, além da análise dos resultados alcançados, nos permite compreender melhor o contexto da materialização das políticas públicas educacionais também a partir da fala dos entrevistados.

Portanto, foi possível concluir que, embora os resultados tenham tido um leve crescimento - principalmente no último exame realizado em 2019 -, a escola está bem distante de atingir a meta proposta para 2021, que foi de 5,6 para os anos iniciais do ensino fundamental e 5,0 para os anos finais do ensino fundamental.

Outra questão que merece atenção é a ênfase nos índices que se baseiam apenas em fluxo e desempenho. Mesmo que haja melhora nos resultados do último exame, não é possível afirmar que de fato a qualidade do ensino na escola pesquisada teve melhoras, uma vez que o reforço escolar em duas disciplinas acaba afastando a escola dos princípios de uma Educação Integral, configurando apenas como um conjunto de atividades (CAVALIERE, 2014).

Assim, lamentavelmente, as escolas brasileiras ainda vivenciam um momento completamente atípico com o ensino remoto, o que certamente impactará os resultados que as escolas alcançarão, uma vez que os alunos se encontram há mais de um ano afastados das atividades presenciais.

De todo modo, os resultados até aqui alcançados indicam que, mesmo ocorrendo uma sensivel melhora nos índices, somente os anos iniciais do Ensino Fundamental estão avançando na projeção prevista na meta 07 
do PNE (2014-2024). Os anos finais estão abaixo do desejável, o que evidencia que são necessárias políticas equitativas de fomento, visando impulsionar mais o segmento com menor desenvolvimento.

Mesmo com a pressão que as avaliações externas exercem sobre as escolas por melhores resultados, os avanços na escola Amazônia têm sido bem pequenos. Ainda assim, os resultados alcançados podem e devem ser utilizados por toda comunidade escolar a fim de compreender melhor o seu papel na rede pública de ensino. Por essa razão, as Tabelas 1 e 2, que constam neste artigo, são recursos pedagógicos com informações relevantes e necessárias ao processo de planejamento e avaliação interna com toda comunidade, bem como às políticas educacionais implantadas ou em vias de implantação na referida escola.

Portanto, quando observados os resultados, é possivel perceber que há uma desconexão na política de melhoria da qualidade do ensino, inclusive com a ampliação de permanência do aluno na escola, em tempo integral, fato este observado principalmente com relação ao pretendido, ao implantado e ao resultado das ações. Nesse contexto, a gestão da escola tem que administrar essas três questões de modo a garantir, preferencialmente, que os resultados pretendidos sejam alcançados, o que nem sempre tem acontecido, como evidencia o caso da escola "Amazônia".

\section{REFERÊNCIAS}

ARROYO, M. G. O direito ao tempo de escola. Cadernos de Pesquisa, São Paulo, n. 65, p. 3-10, maio 1988.

BERNARDO, E. S.; CHRISTOVÃO, A. C. Tempo de Escola e Gestão Democrática: o Programa Mais Educação e o IBEB em busca da qualidade da educação. Educação \& Realidade, Porto Alegre, v. 41, n. 4, p. 1113-1140, out./dez. 2016.

BRASIL. Constituição da República Federativa do Brasil. Brasília, DF: Senado, 1988.

BRASIL. Lei $\mathbf{n}^{\circ} \mathbf{9 . 3 9 4}$, de 20 de dezembro de 1996. Estabelece as diretrizes e bases da educação nacional. Brasília, DF: Presidência da República, 1996. 
BRASIL. Portaria n 931, de 21 de março de 2005. Brasília, DF: Ministério da Educação, 2005.

BRASIL. Decreto $n^{\circ}$ 6.094, de 24 de abril de 2007. Dispõe sobre a implementação do Plano de Metas Compromisso Todos pela Educação. Brasília, DF: Presidência da República, 2007a.

BRASIL. Portaria Normativa Interministerial $n^{\circ}$ 17, de 24 de abril de 2007. Institui o Programa Mais Educação. Brasília, DF: Presidência da República, 2007b.

BRASIL. Portaria n 1.144, de 10 outubro de 2016. Institui o Programa Novo Mais Educação, que visa melhorar a aprendizagem em língua portuguesa e matemática no ensino fundamental. Diário Oficial da União, Brasília, DF, n. 196, 11 out. 2016 a. Seção 1, p. 23.

BRASIL. Programa Novo Mais Educação: Caderno de Orientações Pedagógicas-Versão I. Brasília, 2017a. Disponível em: http://portal.mec.gov.br/docman/agosto-2017-pdf/70831-pnme-cadernode-orientacoes-pedagogicas-pdf/file. Acesso em: 20 abr. 2020.

BRASIL. Saiba Mais - Programa Mais Educação. Ministério da Educação, [online], [20--]. Disponível em: <tinyurl.com/4mja34tu>. Acesso em: 20 abr. 2020.

BRASIL. Saiba Mais - IDEB. Ministério da Educação, [on-line], [20--]. Disponível em: < http://portal.mec.gov.br/conheca-o-ideb>. Acesso em: 20 abr. 2020.

CAVALIERE, A. M. Escola pública de tempo integral no Brasil: filantropia ou política de Estado? Educ. Soc. Campinas, v.35, n 129, p. 1205-122, out-dez, 2014.

CHIRINÉA, A. M.; BRANDÃO, C. F. O IDEB como política de regulação do Estado e legitimação da qualidade: em busca de significados. Ensaio: aval. pol. públ. Educ., Rio de Janeiro, v. 23, n. 87, p. 461-484, abr./jun. 2015.

HOJAS, V.F. Avaliação externa em larga escala e qualidade de ensino na escola básica: as diretrizes legais e os textos oficiais em análise. In:

NOGUEIRA, M. E. (Org.). Gestão Escolar e políticas públicas educacionais: um embate entre o prescrito e o real. Curitiba: Appris, 2013. p. 629-644.

LIBÂNEO, J. C.; OLIVEIRA, J. F.; TOSCHI, M. S. Educação escolar: políticas, estrutura e organização. São Paulo: Cortez, 2007.

LIMA, L. C. Aprender para ganhar, conhecer para competir: sobre a subordinação da educação na "sociedade da aprendizagem". São Paulo: Cortez, 2012.

MOLL, J. A agenda da educação integral: compromissos para sua consolidação como política pública. In: MOLL, J. et al. (Org.). Caminhos da Educação Integral no Brasil: direito a outros tempos e espaços educativos. Porto Alegre: Penso, 2012. p. 129-146. 
MORAES, M. F. A influência da infraestrutura no desempenho escolar: estudo de caso de três escolas do estado do Rio de Janeiro. 138 f. 2014. Dissertação (Mestrado Profissional em Gestão e Avaliação da Educação Pública) Universidade Federal de Juiz de Fora, Juiz de Fora, 2014.

OLIVEIRA, I. B. Políticas Curriculares no contexto do golpe de 2016: debates atuais e resistências. In: AGUIAR, M. A. S.; DOURADO, L. F. (Org). A BNCC na contramão do PNE 2014-2024: avaliação e perspectivas. Recife: ANPAE, 2018. p. 55-59.

OLIVEIRA, N. C. M.; SOUZA, O. N. B. A lógica de programas na política educacional brasileira e paraense: uma agenda de estudos. Belém: Editora Cromos, 2015.

PARO, V. H. Crítica da estrutura da escola. São Paulo: Cortez, 2011.

PARO, V. H. Diretor escolar: educador ou gerente? São Paulo: Cortez, 2015.

PARO, V. H. Gestão democrática da educação pública. 4. ed. São Paulo: Cortez, 2016.

PAZ, F. M. Contribuições para o debate sobre a escola pública: o Índice de Desenvolvimento da Educação Básica (Ideb). In: OLIVEIRA, M. E. N. (Org.). Gestão Escolar e políticas públicas educacionais: um embate entre o prescrito e o real. Curitiba: Appris, 2013.

RINALDI, R. P.; RINALDI, J. G. S. A formação e a prática de oficineiros em escolas com jornada ampliada. Revista Exitus, Santarém, v. 10, p. 1-28, e020026, 2020.

SATYRO, N.; SOARES, S. A infraestrutura das escolas brasileiras de ensino fundamental: um estudo com base nos censos escolares de 1997 a 2005. Brasília: IPEA, 2007.

SCHNIDER, M. P.; NARDI, E. L. O IDEB e a construção de um modelo de accountability na educação básica brasileira. Revista Portuguesa de Educação, Braga, v. 27, n. 1, p. 7-28, 2014.

VIEIRA, S. L. Gestão, avaliação e sucesso escolar: recorte da trajetória cearense. Estudos Avançados, São Paulo, v. 21, n. 60, p. 45-60, ago. 2007.

Recebido em: 12 de julho de 2021. Aprovado em: 13 de outubro de 2021. Publicado em: 11 de dezembro de2021. 